\title{
Use of Radiographic Densitometry to Predict the Bone Healing Index in Distraction Osteogenesis
}

\author{
A Saw, FRCS (Edin), S Manimaran, MS Ortho (UM), S Faizal*, MRad (UM), AM Bulgiba**, PhD (East Anglia) \\ Department of Orthopaedic Surgery, University Malaya Medical Centre, Kuala Lumpur, Malaysia \\ * Department of Biomedical Imaging, University Malaya Medical Centre, Kuala Lumpur, Malaysia \\ ** Department of Social and Preventive Medicine, University Malaya Medical Centre, Kuala Lumpur, Malaysia
}

\begin{abstract}
Bone lengthening with distraction osteogenesis involves prolonged application of an external fixator frame. Qualitative and quantitative evaluation of callus has been described using various imaging modalities but there is no simple reliable and readily available method. This study aims to investigate the use of a densitometer to analyze plain radiographic images and correlate them with the rate of new bone formation as represented by the bone healing index. A total of 34 bone lengthening procedures in 29 patients were retrospectively reviewed. We used an X-Rite 301 densitometer to measure densities of new callus on plain radiographs taken at 4 and 8 weeks after surgery. Patients aged below 16y had significantly lower BHIs indicating faster bone healing and shorter duration of treatment. The ratio of radiographic densities between centre and edge of the new bone measured from plain radiographs taken at 8 weeks correlated positively with the eventual BHI of the patient. This method provides a simple and easy way to predict the rate of bone healing at an early stage of treatment and may also allow remedial action to be taken for those with poor progress in bone formation.
\end{abstract}

Key Words:

Bone lengthening, Bone healing index, Densitometer, Callus, Centre/Edge ratio

\section{INTRODUCTION}

Indication for bone lengthening procedures has increased since its introduction by Ilizarov ${ }^{1}$. With gradual distraction of a bone that is broken in a controlled manner, additional length can be gained and deformity can be corrected. This is usually achieved by an external fixator. Although the basic principle of bone lengthening (usually referred to as distraction osteogenesis) is relatively simple, the procedure is associated with a high rate of complications ${ }^{2,3}$. As this procedure involves prolonged treatment, its use remains relatively limited and problems arise due to the long duration of external fixation.
The Bone Healing index (BHI) relates the length of time a patient undergoes treatment with an external fixator to the measured length of bone gained ${ }^{2}$. The index is calculated after completion of bone lengthening treatment. Early prediction of the BHI is potentially useful for several reasons. When there is early evidence of poor bone formation, the surgeon can investigate contributing factors and take appropriate remedial actions such as include dynamization or loading of the bone. For new bone that is healing too rapidly, a faster rate of distraction can be applied to avoid premature consolidation of the distraction site.

Catagni ${ }^{4}$ classified the gross appearance of the callus on plain radiograph and recommended modification of the distraction rate based on the findings. Inter-observer variability is significant because such description is rather subjective. On the other hand, ultrasonography findings correlate well with stiffness of the callus especially in the early stages, however correlation with eventual outcome of bone healing is not established ${ }^{5}$. Others have considered regular assessment with quantitative CT scanning ${ }^{6}$ or dualenergy x-ray absorptiometry (DEXA) scan to monitor the change in bone mineral density ${ }^{7}$ during the lengthening process. These examinations are relatively expensive and are not readily available in many hospitals.

On the other hand, a densitometer is a simple apparatus that has previously been used for quantifying the degree of light penetration across photographic films and plain radiographs $^{8}$. The cost of a densitometer is comparable to that of one basic desktop computer and cheaper than most other medical equipment. We therefore decided to investigate the use of a densitometer to provide a more objective evaluation of callus formation by comparing radiographic densities between original and new bone.

\section{MATERIALS AND METHODS}

Patients who underwent bone lengthening procedure in this institution between January 1998 and December 2001 were retrospectively reviewed. Those who completed the 
treatment in other institutions were excluded since final outcome of born healing will not be available for evaluation. Demographic data and details of treatment were recorded. Application of the external fixator and corticotomy were performed in the same operative procedure. Gradual lengthening of the bone was started after a latent period of 1 to 2 weeks after the surgery, and lengthening was discontinued when desired correction was achieved; the external fixator will not be removed until there was evidence of cortex formation in 3 out of 4 new bone margins in anteroposterior and medial-lateral plain radiographs. Plain radiographs were retrieved from the department of biomedical imaging. The level, pattern and translation of the corticotomy site were also recorded and analyzed for correlation with BHI.

We used the X-Rite 301 Densitometer (Michigan, United States) for measuring light penetration of plain radiographic films. The film was placed on the illuminated platform of the densitometer so that the point for measurement was located below the reader. The reader was then lowered to the surface of the film (Fig. 1). Different areas of the radiographic film can be measured by changing the position of the film. The reading area of this densitometer is $2 \mathrm{~mm}$ in diameter. Lower readings indicate higher bone density and vice-versa $^{8}$. Plain anterior posterior radiograph of the distraction gap at 4 and 8 weeks were selected for measurement. All measurements were performed by the authors. Readings were taken at specific locations on each film (Fig. 2): (a) on the original bone $5.0 \mathrm{~mm}$ away from the proximal and distal bone edge $\left(\mathrm{M}^{1}\right.$ and $\left.\mathrm{M}^{2}\right)$; (b) on the new bone $3.0 \mathrm{~mm}$ away from the proximal or distal bone edge $\left(\mathrm{E}^{1}\right.$ and $\left.\mathrm{E}^{2}\right)$; (c) in the middle section of the new bone $(\mathrm{N})$. We calculated the centre/edge ratio ( $\mathrm{C} / \mathrm{E}$ ratio) and edge/medullary ratio (E/M ratio) for each patient (Fig. 3) and plotted it against the BHI.

Data entry analysis was conducted using SPSS, version 15 for Windows. Clinical and radiological data were analyzed using the chi-square test, t-test, Mann-Whitney and KruskalWallis test. A p-value of less than 0.05 was considered significant.

\section{RESULTS}

Thirty-two patients were treated with bone lengthening procedure during the study period, but 3 patients were excluded due to incomplete follow up records. In the remaining 29 patients, the mean age was $12 \mathrm{y}$ (range, 3 to 45y). There were 18 males and 11 females. In 15 patients, the underlying pathology was related to trauma, while in the remaining 14, the deformity was either congenital or developmental in nature. A total of 34 procedures were performed in the 29 patients. Two patients with generalized bony dysplasia required ulnar bone lengthening to be repeated; one patient with spondylometaphyseal dysplasia had simultaneous lengthening of femur and tibia; one patient with enchondromatosis had one lengthening of the femur and repeated lengthening of the same tibia. Fourteen patients developed some degree of joint stiffness during treatment; three, peroneal nerve deficit; one, re-fracture of the callus; and one, premature consolidation. The 3 cases of neurological deficits developed during the lengthening phase of treatment.

The mean BHI for the study sample was 1.2 (min 0.8 and max 1.8), indicating that a mean of 1.2 months were required for every centimetre of bone lengthened. There was no significant difference in the BHI between male (1.1) and female (1.2) based on the Mann-Whitney analysis. When patients are grouped by age at treatment, those below 16y (range 3 to 16y) had a lower BHI (1.0) compared to those $16 \mathrm{y}$ and above (1.3), a difference that is statistically significant (Table I).

Corticotomy was performed at the proximal $3 \mathrm{rd}$ in 24 procedures, middle $3 \mathrm{rd}$ in 4 procedures and distal $3 \mathrm{rd}$ in 6 procedures. Based on post-operative radiographs, 10 corticotomies resulted in translation between 10 to $20 \%$ of the cross section while the remaining were less than $10 \%$. Regarding corticotomy pattern, the cut was transverse in 23 procedures and either oblique or comminuted in the remaining 11 procedures. When we compared the BHI regarding the level, translation and pattern of corticotomies, the differences were not statistically significant (Table I).

We compared the Edge Medullary (E/M) and Centre Edge $(\mathrm{C} / \mathrm{E})$ ratios at 4 weeks and 8 . There was no significant difference in the ratios between the proximal and distal ends of corticotomy (between $\mathrm{E}^{1} / \mathrm{M}^{1}$ and $\mathrm{E}^{2} / \mathrm{M}^{2}$; between $\mathrm{C} / \mathrm{E}^{1}$ and $\mathrm{C} / \mathrm{E}^{2}$ ) at 4 or 8 weeks. We therefore used the mean of the proximal and distal readings to generate $\mathrm{E} / \mathrm{M}\left(\mathrm{E}^{1}+\mathrm{E}^{2} / \mathrm{M}^{1}+\mathrm{M}^{2}\right)$ and $\mathrm{C} / \mathrm{E}$ $\left(\mathrm{C} / \mathrm{E}^{1}+\mathrm{E}^{2}\right)$ for correlation with BHI. (Fig. 3)

There was an increasing trend of $\mathrm{E} / \mathrm{M}$ ratio corresponding to BHI at 4 weeks and 8 weeks but they were not statistically significant (not shown). When we look at the $\mathrm{C} / \mathrm{E}$ ratio and BHI, we observed a correlation between these measures at 8 weeks (Fig. 4) but not at 4 weeks, indicating that patients with lower $\mathrm{C} / \mathrm{E}$ ratio at 8 weeks can expect to have a lower $\mathrm{BHI}$ and will require shorter time for treatment. Based on this data the $\mathrm{BHI}$ is related to the $\mathrm{C} / \mathrm{E}$ ratio at 8 weeks with a Pearson's $\mathrm{r}$ of $0.626(p=)$ and $\mathrm{r}^{2}$ of 0.392 . This means that $39.2 \%$ of the variance in BHI can be explained by the $\mathrm{C} / \mathrm{E}$ ratio alone, without any other predictor present. This can be expressed as a formula such that: $\mathrm{BHI}=\mathrm{C} / \mathrm{E}$ Ratio $* 2.484-$ 1.591.

When we divided the $\mathrm{C} / \mathrm{E}$ ratio into 3 groups: below 1.1, between 1.1 and 1.2, above 1.2, the BHI for these groups were significantly different when tested with the KruskalWallis test (Table II). 
Table I: Clinical, radiological parameters and BHI

\begin{tabular}{|c|c|c|c|c|}
\hline Factor & Description & $\mathbf{N}$ & Mean BHI & Mann-Whitney p-value \\
\hline \multirow[t]{2}{*}{ Age } & Less than 16yrs & 12 & 1.0 & \multirow[t]{2}{*}{$p<0.05$} \\
\hline & 16 or above & 17 & 1.3 & \\
\hline \multirow[t]{2}{*}{ Sex } & Male & 18 & 1.1 & \multirow[t]{2}{*}{$p=0.21$} \\
\hline & Female & 11 & 1.2 & \\
\hline \multirow[t]{4}{*}{ Underlying pathology } & Trauma (no infected) & 10 & 1.3 & \multirow[t]{4}{*}{$p=0.21$} \\
\hline & Trauma (active infection) & 5 & 1.2 & \\
\hline & Congenital / Bony Dysplasia & 5 & 1.1 & \\
\hline & Others & 6 & 1.1 & \\
\hline \multirow[t]{3}{*}{ Level of Corticotomy } & Proximal 3rd & 24 & 1.1 & \multirow[t]{3}{*}{$p=0.31$} \\
\hline & Middle 3rd & 4 & 1.4 & \\
\hline & Distal 3rd & 6 & 1.2 & \\
\hline \multirow[t]{2}{*}{ Translation of corticotomy } & Less than $10 \%$ & 24 & 1.1 & \multirow[t]{2}{*}{$\mathrm{p}=0.21$} \\
\hline & Between 10 to $20 \%$ & 10 & 1.2 & \\
\hline \multirow[t]{2}{*}{ Pattern of Corticotomy } & Transverse & 23 & 1.2 & \multirow[t]{2}{*}{$p=0.15$} \\
\hline & Oblique / comminution & 11 & 1.3 & \\
\hline
\end{tabular}

$\mathrm{BHI}=$ Bone healing index (month per centimetre)

Table II: Centre/Edge ratio sub-classification with Bone Healing Index

\begin{tabular}{|c|c|c|c|}
\hline C/E Ratio & $\mathbf{N}$ & Mean rank BHI & p-value \\
\hline$<1.1$ & 19 & 10.89 & 0.001 \\
\hline $1.1-1.2$ & 6 & 21.33 & \\
\hline$>1.2$ & 4 & 25.00 & \\
\hline $\mathrm{C} / \mathrm{E}$ ratio & & & \\
\hline
\end{tabular}

\section{DISCUSSION}

Bone lengthening procedures have evolved from the use of skeletal traction by Codivilla ${ }^{9}$, to the gradual, controlled traction technique of Vittorio Putti ${ }^{10}$, to the uniplanar distraction device by Wagner ${ }^{11}$ to the ring external fixator by Ilizarov ${ }^{1}$. Introduction of principles related to distraction osteogenesis by Ilizarov have made this method popular for reconstruction or salvage of deformed limbs.

A previous study reports that new bone formation is better when corticotomy is performed at the metaphysis instead of the diaphysis ${ }^{12}$. In this study, we were not able to demonstrate any association between level, pattern and translation of corticotomy with BHI for external fixation. It appears that biological factors influence bone healing more than these physical variations.

Problems related to the Ilizarov method of bone lengthening can arise during surgery, the period of gradual distraction or the period awaiting bone consolidation (2). Gradual distraction remains the most problematic period. Although one centimetre a day is the most common rate of distraction for bone lengthening, the rate may be adjusted to avoid premature or delayed consolidation of the new bone. In addition, adjuvant measures including mechanical stimulation or chemical enhancement may be considered for those expected to have poor bone formation.
Current practice in callus assessment depends mainly on radiological appearance of the new bone. Catagni ${ }^{4}$ classified the callus into normotrophic, hypertrophic and hypotrophic based on radiographic appearances at 20 to 30 days after corticotomy, but correlation with rate of healing was not analysed. Hamanashi et al ${ }^{13}$, on the other hand, recommended a more detailed description of the callus and developed 6 groups: external, straight, attenuated, opposite, pillar, and agenetic. Although the Hamanashi study demonstrated correlation between radiographic appearance and BHI, inter-observer variation remains a problem. In a more recent study, Donnans et $a{ }^{14}$ recommended 3 groups of callus categories: regenerate outline (4 types), regenerate polarity (2 types) and regenerate consistency (4 types). However, results of the Donnans study do not reveal a significant correlation that reliably predicts the rate of bone healing. The study also recognised the problem of interobserver variability and suggested digitization and enhancement of plain radiographs to decrease variability.

In the present study, densitometry measurements were taken from well defined sites on radiographs. The densitometer is portable, easy to use and inexpensive. With the positive correlation between $\mathrm{C} / \mathrm{E}$ ratio and $\mathrm{BHI}$, we will be able to appropriately recommend intervention for patients whose ratio is too low or too high. A higher rate of distraction can be considered for those with a $\mathrm{C} / \mathrm{E}$ ratio less than 1.0 and enhancement can be considered for those with $\mathrm{C} / \mathrm{E}$ ratio greater than 1.2. 


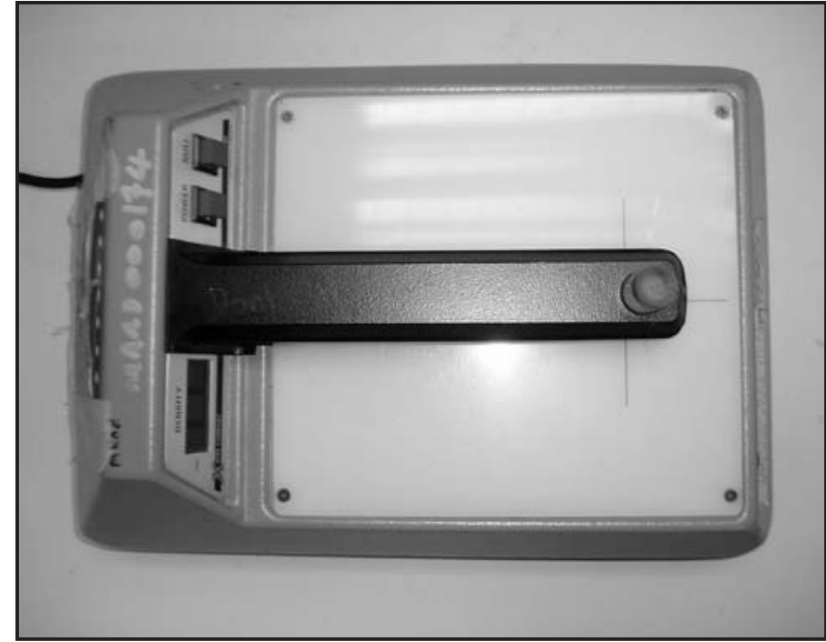

Fig. 1: X-Rite (301) densitometer.

Edge / medullary ratio $(E / M$ ratio $)=\left(E^{1}+E^{2}\right) /\left(M^{1}+M^{2}\right)$

Centre / edge ratio (C/E ratio) $=\mathrm{C} /\left(\mathrm{E}^{1}+\mathrm{E}^{2}\right)$

Fig. 3: Calculation of E/M ratio and C/E ratio.

Due to limited number of subjects, we were not able to perform analysis based on individual bones. The small number of patients prohibits more sophisticated analysis and we were unable to perform multivariate analysis here.

\section{CONCLUSION}

Measurement of image densities of plain radiographs by densitometer can be useful to evaluate clinical progress of bone lengthening procedure. $\mathrm{C} / \mathrm{E}$ ratio 8 weeks after surgery correlates to BHI of treatment, and is helpful for a clinician to individualize the treatment to achieve a shorter duration of treatment. The level, pattern and translation of the corticotomy do not influence the rate of formation of new bone.

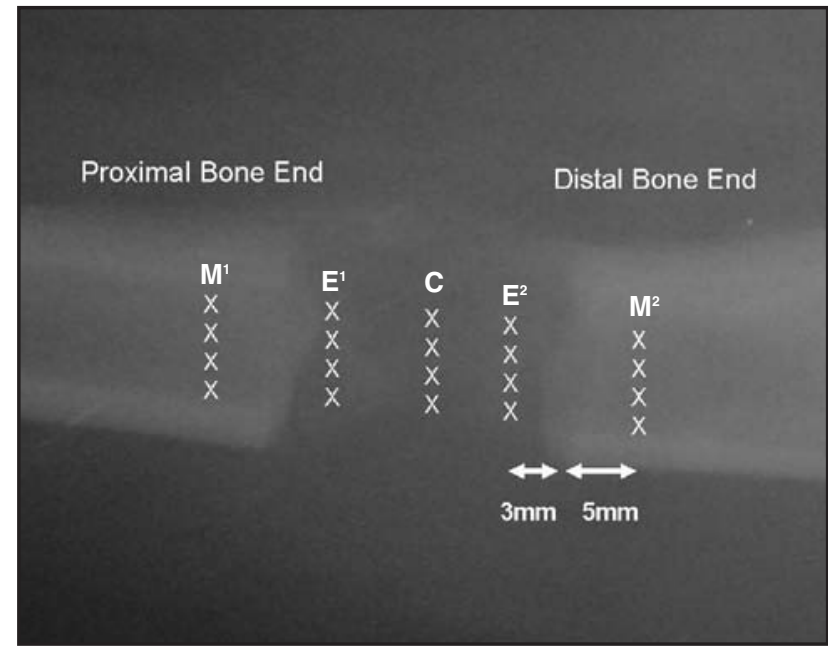

Fig. 2: Points of densitometer measurements on plain radiographs.

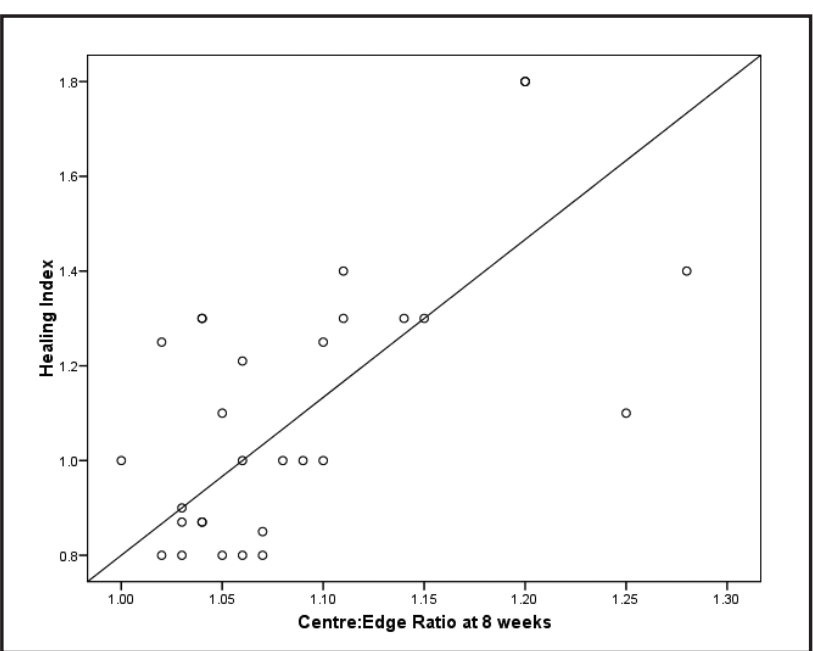

Fig. 4: Bone Healing Index versus Centre/Edge ratio at 8 weeks. 


\section{REFERENCES}

1. Aronson J, Bianchi MA. The biology of distraction osteogenesis. In Operative Principles of Ilizarov. Fracture Treatment, Nonunion, Osteomyelitis, Lengthening, Deformity Correction. Baltimore: Williams and Wilkins; 1991: 42-52.

2. Paley D. Problems, obstacles and complications of limb lengthening by the Ilizarov techniques. Clin Orthop. 1990;250:81-104.

3. Aquerreta JD, Forriol F, Canadell J. Complications of bone lengthening. Internal Orthop. 1994; 18: 299-303.

4. Catagni M, Maiocchi AB, Aronson J, eds. Imaging techniques: the radiographic classification of bone regenerate during distraction. In Operative Principles of Ilizarov. London: Williams \& Wilkins; 1991: 53-7.

5. Hermann JB, Kolbeck S, Krummrey G, Weiler A, Windhagen HJ, Hennies K, Raun K, Raschke MJ. Ultrasound can Predict Regenerate Stiffness in Distraction Osteogenesis. Clin Orthop. 2002; 404: 362-7.

6. Tselentakis G, Owen PJ, Richardson JB, Kuiper JH, Haddaway MJ, Dwyer JSM, Evans GA. Fracture Stiffness in Callotasis Determined by Dual-Energy X-Ray Absorptiometry Scanning. J Peds Orthop (B) 2001; 10: 248-54.

7. Harp JH, Aronson J, Hollis M. Noninvasive determination of bone stiffness for distraction osteogenesis by quantitative computed tomography scans. Clin Orthop. 1994; 301: 4248.

8. Schramel FM, Golding RP, Haakman CD, Sutedja TG, de Jong KA, Postmus PE. Expiratory chest radiographs do not improve visibility of small apical pneumothoraces by enhanced contrast. Eur Respir J. 1996; 9(3): 406-9.

9. Codivilla A. On the means of lengthening, in the lower limbs, the muscles and tissues which are shortened through deformity. Am J Orthop. 1905; 2: 353.

10. Putti V. The operative lengthening of the femur. JAMA. 1921; 77: 934-5.

11. Wagner H. Operative lengthening of the femur. Clin Orthop. 1978; 136: 125-42.

12. Aronson J, Shen X. Experimental healing of distraction osteogenesis comparing metaphyseal with diaphyseal sites. Clin. Orthop. 1994; 301: 25-30.

13. Hamanishi C, Yasuwaki Y, Kikuchi H, Tanaka S, Tamura K. Classification of the callus in limb lengthening: radiographic study of 35 limbs. Acta Orthop Scand. 1992; 63(4): 430-3.

14. Donnan LT, Saleh M, Rigby AS, McAndrew A. Radiographic Assessment of Bone Formation in Tibia During Distraction Osteogenesis. J Ped Orthop. 2002; 22: 645-51. 